\title{
Design and Analysis of Carbon Fibre Composite Monorack Arm for Motorcycle
}

\author{
A Ridzuan*, T Jagan \\ Department of Mechanical \& Mechatronic Engineering, Faculty of Engineering, Technology and Built Environment, \\ UCSI University, Kuala Lumpur, 56000, MALAYSIA \\ *Corresponding Author
}

DOI: https://doi.org/10.30880/ijie.2019.11.07.020

Received 09 October 2019; Accepted 25 October 2019; Available online 15 November 2019

\begin{abstract}
Monorack arm in the motorcycle is invented for the support of external topbox. However, load-bearing of the typical monorack arm made of common engineering metals is restricted to only 3 kilograms by the manufacturer in which exceeding this load may result in failure. Therefore, alternative materials such as carbon fibre composite receives the spotlight for this project. With that being said, the project objectives were to propose several conceptual designs of monorack arm which were used to analyze with finite element methods. Next, fabrication of carbon fibre composite sample was required to perform experimental analysis. Accordingly, several conceptual designs of monorack arm in regard to design considerations under static stress application were established. Besides, 2 types of samples were fabricated for experimental analysis namely plain weave woven fabric carbon fibre and twill weave woven fabric carbon fibre. Samples of carbon fibre composites were fabricated to possess a higher fibre volume fraction than the matrix to add fibre strength in the composite. Final conceptual designs of monorack made were computed for structural analysis using ANSYS Workbench. During the simulation of conceptual models, conceptual design 2 of epoxy carbon woven $(230 \mathrm{GPa})$ wet was found to show better structural results in comparison to other designs using the same material. Lastly, tensile test was performed on the fabricated test specimens of plain weave carbon fibre and twill weave carbon fibre according to ASTM standards whereby favorable results were shown to plain weave woven fabric carbon fibre.
\end{abstract}

Keywords: Monorack arm, carbon fibre, conceptual design, plain weave, twill weave

\section{Introduction}

The idea of the invention called monorack arm is basically to support the rear compartment box or topbox with a pair of tubular shaped arms which runs at the sides of the motorcycle. This research focuses on monorack arm designs to exceed the current maximum load-bearing which results in failure or breakage of the arm when being subjected to a load of $3 \mathrm{~kg}$ as restricted by the GIVI manufacturer. The next area of interest was intensive study about carbon fibre composites and their behaviors towards automobile applications. Carbon fibre composites are leading the race and are becoming more and more essential in various fields including automobile sector and the market is expected to grow even further. Hence, the relationship between monorack arm and carbon fibre composite were investigated to tackle the problem statement associated with the study.

GIVI is one of the leading manufacturers in producing quality motorcycle accessories including these racking system and various type of top boxes. The application of these racking system in conjunction with compartment box is becoming more common among the motorcycle users as they provide a safe, secured and yet a big storage box for the users to keep their belongings. There are two types of racking system which are Monotech Rack (MV) and Heavy-duty Rack (HRV). MV is a basic type of racking which is mounted on the rear hand bar of the motorcycle. HRV is an advanced racking system which is extended to the mid part of the motorcycle for a very firm attachment and to provide 

better stability. For the current design of monorack arm in the market made of engineering metals, the maximum load bearing is restricted to 3 kilograms. Development of composite materials in vast applications especially in automotive industry can be the best solution to serve as an alternative material to produce these monorack arms to yield an improved load bearing compared to the existing load [1]. Composite materials receive such great acceptance than any other conventional materials because of their inherent properties and higher loading capacity [2]. Composite material comprises of two or more parts or elements to achieve an aggregate behavior of properties which are contrast to its parent elements [3].

Uses of composites in various fields are growing rapidly due to the fact of their outstanding properties [4]. Due to its lightweight characteristic, composite materials have been implemented to use on aerospace structures allowing a reduction of $50 \%$ of total weight [5]. Major importance is given to composite materials of today's manufacturing as a proper material selection can minimize the overall weight of the vehicle which would maximize the fuel efficiency and consequently will result in a lower emission of harmful pollutants. Technological advancement has been demanding a new material which possesses exceptional properties which could challenge the current materials used for various of applications [6]. Innovation in materials engineering have introduced carbon fibre which marks as an important manufacturing material due to its numerous advantages in engineering use. Carbon fibre is a very strong and stiff material making the use in various applications. Over recent decades, polyacrylonitrile (PAN) carbon fibres are the majority production followed by pitch and rayon carbon fibres [7]. The manufacturing of carbon fiber can be divided into 4 steps which are precursor fabrication which is based on polyacrylonitrile (PAN), stabilization, carbonization and surface treatment [8]. Mass production of carbon fibre is being limited due to the carbon fibre production process which involves high energy demand associated with environmental impacts. Carbon Fibre Reinforced Polymer (CFRP) are known as the 21 st century advanced composite material being integrated in automotive field as it comprises of numerous advantages [9].

CFRP uses carbon fibre as reinforcement which is being imbedded in matrix known as polymer. The idea of this reinforcement and matrix to form composite works in a way that the carbon fibre takes the major load and the polymer matrix provides the necessary support to protect the fibers. Primarily, the properties of a composite material are highly dependent on the type of fibre being used as the reinforcement [10]. Advantages associated with carbon fibre composites are high strength-to-weight ratio, high stiffness-to-weight ratio, extensive fatigue life, minimal weight, corrosion and wear free and stable on environmental conditions [11].

This research paper is to study the relationship of Plain weave carbon fibre composite and Twill weave carbon fibre composite on different monorack arm of existing and conceptual designs for optimum performance upon loading. To the best knowledge, an intensive study about the relationship of Plain weave carbon fibre and Twill weave carbon fibre on mechanical structure is limited. Hence, this research comprises of the following objectives. First and foremost, several conceptual designs of monorack arm to be developed and proposed. Next, a sample of carbon fibre composite must be fabricated and the final objective is to analyze the conceptual designs and sample of carbon fibre composite using Finite Element Analysis and experimental methods.

\section{Methodology and Experimental Setup}

\subsection{Conceptual Designs of Monorack Arm}

Several designs of monorack arm were proposed in order to withstand a load of 1.5 kilogram on each side of the arm which totals up to 3 kilograms without resulting in failure or breakage of the arm. Reference monorack arm design of Honda RS 150 with a fitting of Heavy-duty racking (HRV) as shown in Figure 1 below was used for enhancement and improvement of the current design.

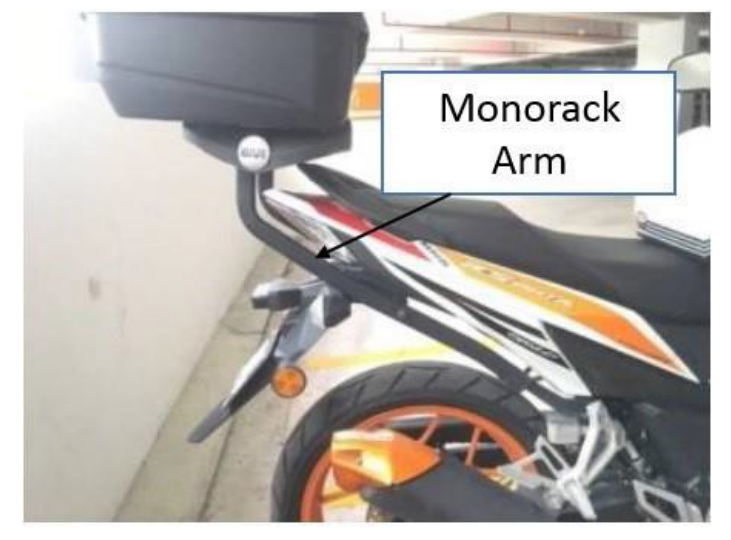

Fig. 1 - Honda RS 150 heavy-duty monorack arm 
A few conceptual sketches of monorack arm designs were firstly initiated. Proposed conceptual sketches can be distinguished by the appearance and specifications. Monorack arm designs were then converted into three-dimensional drawing using CAD drawing with an actual scale of 1:1. SolidWorks version 2018 was used for the solid modeling of all the final conceptual designs of monorack arm. Conceptual designs were established by the insertion of a pair of straight slots which makes the thickness of the hollow design of the arm. Lines across the lengthwise of the monorack arm were made which will make up the path for the extrusion. Fillets and angles of entities we re specified accordingly. With a fully defined profile and path, swept boss/base tool was selected and a preview of the part was shown.

A piece of base plate support was drawn according to the dimensions by adding lines which were extruded to the desired thickness. Mate tool was selected to offset base plate support to the center distance of the monorack arm. Extrude cut tool was used to create the clearance bolt holes as the attachment points on the monorack arm and top of the base plate support. Design 1 as in Figure 2 below is a conventional design existed in the market. Heavy-duty rack (HRV) whereby the tubular rack has extension to the mid-section of the motorcycle to provide firm support and to maximize the stability. Pair of this design consists of four attachment points at the sides of the motorcycle and four attachment points for the base plate on the base plate support of the monorack arm. Four units of bolts and nuts were used to fasten the monorack arm to the body frame. Similarly, four units of bolts and nuts were used as fasteners to secure the base plate where the top box was locked.

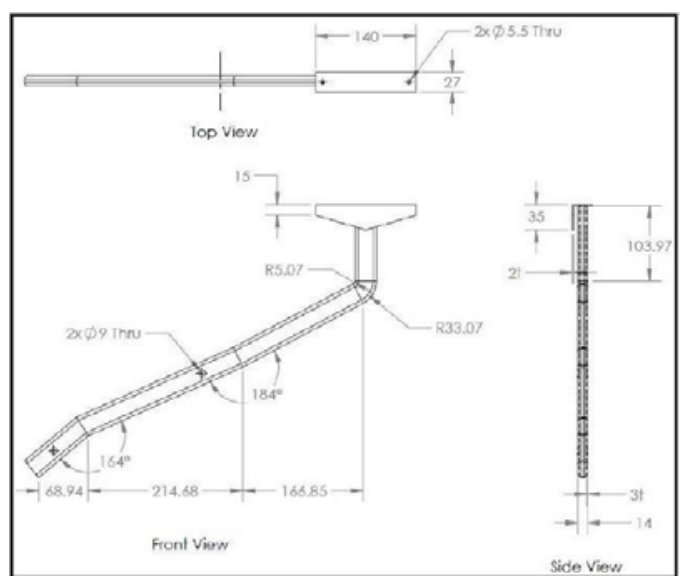

(a)

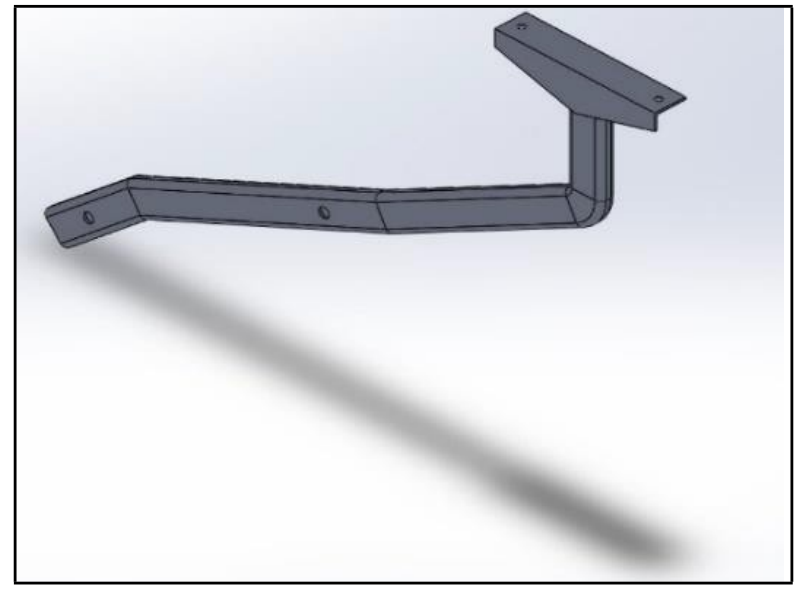

(b)

Fig. 2 - (a) Orthographic; (b) Isometric views of existing design 1

Design 2 as in Figure 3 below was designed as a pair of tubular shaped monorack arms, which it will be integrated on both sides of the motorcycle. A total of four arms running at the sides of the motorcycle can withstand a higher static structural load. Eight attachment points at the sides of the motorcycle and four attachment points for the base plate on the base plate support were added to the current design. Type of fasteners used were eight bolts and nuts to secure the monorack arm and four bolts and nuts to lock the base plate together with top box.

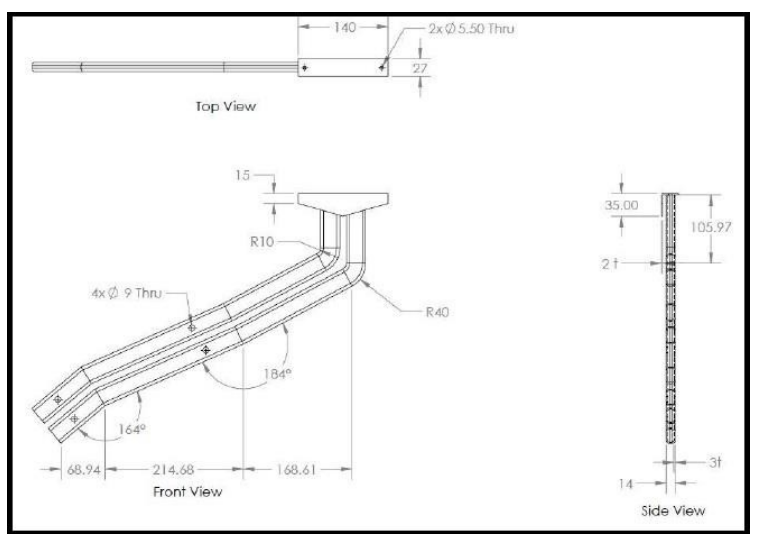

(a)

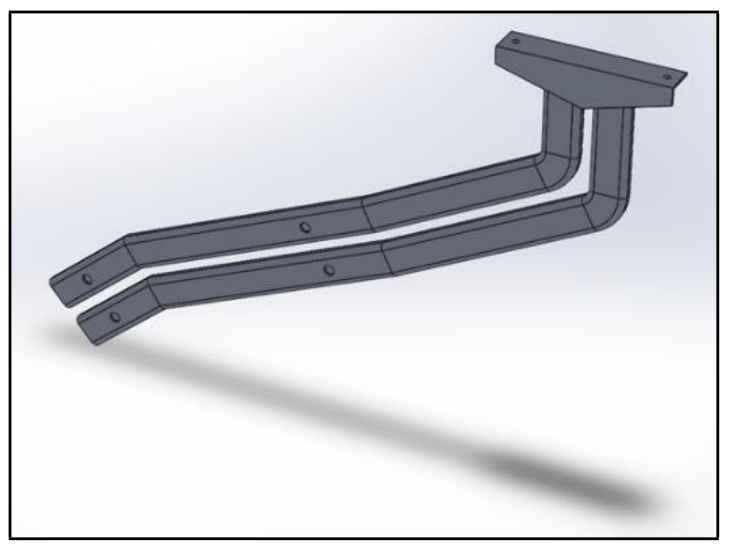

(b)

Fig. 3 - (a) Orthographic; (b) Isometric views of final conceptual design 2 
Design 3 as in Figure 4 below was designed as a single arm that splits into two to give a superior support to the base plate and compartment box. The arm was likewise of tubular shape. Design consists of four attachment points at the sides of the motorcycle and four attachment points for the base plate. Model of monorack arm was fastened by the means of bolts and nuts at the corresponding bolt holes. A total of four bolts and nuts were used to secure the monorack arm while four bolts and nuts to place the base plate and top box.

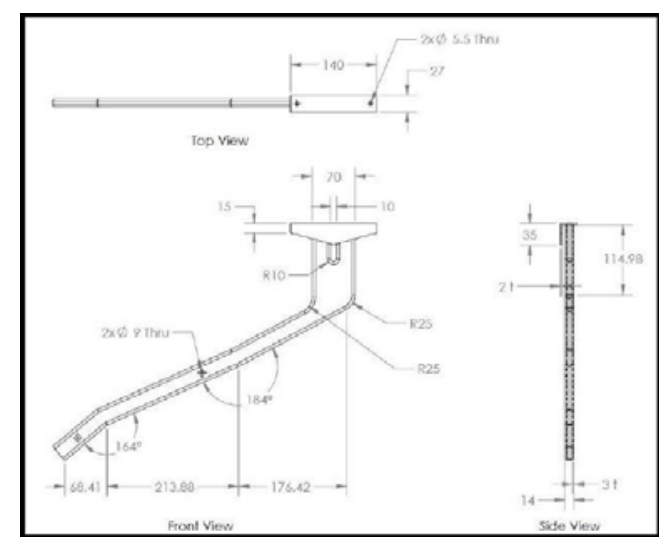

(a)

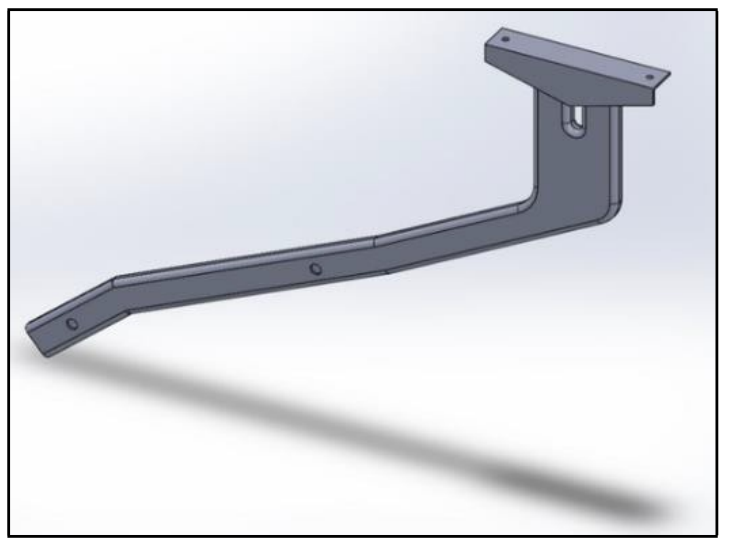

(b)

Fig. 4 - (a) Orthographic; (b) Isometric views of final conceptual design 3

\subsection{Hand Lay-Up Technique}

Hand lay-up technique was used as this is the most cost-effective method in fabricating carbon fibre composite which requires the least equipment compared to other fabricating methods. For the present work, two types of woven fabric have been used as the reinforcement for each of the sample fabrication which were plain weave carbon fibre woven fabric and twill weave carbon fibre woven fabric. Fabrication was firstly started with the application of mold release wax to the entire surface of the mold. A proportion of 2:1 of epoxy resin to hardener ratio as the matrix phase was used. Application of the first layer of epoxy resin was deposited on the entire surface of the mold followed by laying the first layer of fabric. The fabric was impregnated to make intimate contact with the mold surface with the help of finned roller and bubble buster roller. Second layer of epoxy resin application was done to wet out the fabric laid. Steps to sandwich fabric in between the epoxy resin was repeated up to 8 layers of laminates. Samples were left at room temperature for a curing time of 48 hours before demolding and trimming. Fabricated samples after curing are as shown in Figure 5.

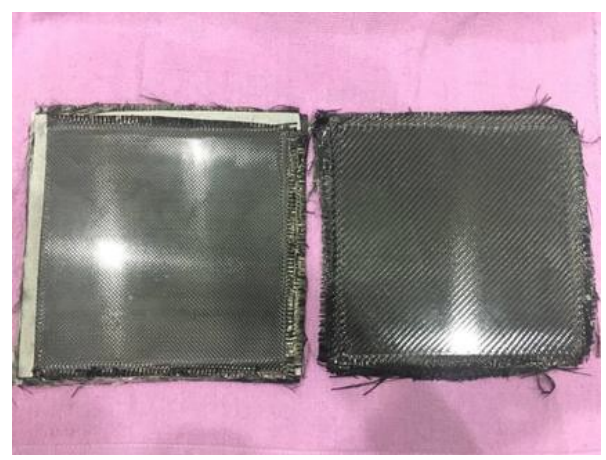

Fig. 5 - Plain weave carbon fibre sample (left) and twill weave carbon fibre sample (right)

\subsection{Finite Element Analysis}

The simulation of the final conceptual designs of the monorack arm were done using ANSYS Workbench 19.2 Student Version. ANSYS Composite PrePost (ACP) was used to build the composite material on the final conceptual designs prior to the analysis. Firstly, epoxy carbon woven $(230 \mathrm{GPa})$ wet was selected under the outline of composite materials which was then chosen as the material assignment for the conceptual design. Mesh sizing for the monorack arm design was inserted to be $2 \mathrm{~mm}$ after the geometry selection. New fabric was created whereby the ply material was chosen to be epoxy carbon woven $(230 \mathrm{GPa})$ wet and the ply thickness was assigned to be $0.3 \mathrm{~mm}$. Modeling group was created to develop 10 plies for the design with an alternating ply angle of $0^{\circ}$ and $90^{\circ}$. Static structural from the toolbox was selected for the structural analysis. Setup from the ACP (Pre) project was transferred as shell composite 
data into static structural project. Taking into consideration a load of $1.5 \mathrm{~kg}$ which will result as a force of $\mathrm{F}=\mathrm{W}=\mathrm{mg}$ $=1.5 \mathrm{~kg} \times 9.81 \mathrm{~m} / \mathrm{s}^{2}$. Thereby, a magnitude of $-14.715 \mathrm{~N}$ was inserted as structural loads of force on top of the base plate support. Fixed supports for the design model were then inserted at the bolt holes faces. Structural analysis of total deformation, equivalent (von-mises) stress and composite failure tool were then computed. Parameters used during finite analysis are demonstrated in Table 1.

Table 1 - ANSYS simulation parameters during finite analysis

\begin{tabular}{l} 
Simulation Parameters \\
\hline Ply Material: Epoxy Carbon Woven $(230 \mathrm{GPa})$ Wet \\
Ply Thickness: $0.3 \mathrm{~mm}$ \\
Number of Plies Stacked: 10 \\
Ply Angles: $0^{\circ}$ and $90^{\circ}$ \\
Boundary Conditions for Static Structural Analysis; \\
• Fixed Support: At the Bolt holes on the Arm \\
- Force of $14.715 \mathrm{~N}$ on the top of the base plate support \\
\hline
\end{tabular}

\subsection{Experimental Analysis}

Specimens of carbon fibre epoxy composite after fabrication were tested for tensile testing. The purpose of the experiment was to investigate the mechanical behavior of carbon fibre epoxy composite upon changing the type of woven fabric consisting of plain weave and twill weave. A total of 4 specimens for each of plain weave woven fabric and twill weave woven fabric were prepared according to ASTM D3039 [13]. Tabbing procedure was done to prevent gripping stress from causing damage and potential failure at inside the grip section of test specimen. Tab material used was mild steel as they were strong metals to resist the pressure from the grip and nevertheless protects the test specimen. The tabs were bonded at both ends of the test specimen using epoxy resin and hardener as adhesive. The tensile test specimen parameters are as shown in Table 2.

Table 2 - Tensile test specimen parameters

Tensile Test Specimen Parameters

Specimen Width $=25 \mathrm{~mm}$

Specimen Thickness $=2 \mathrm{~mm}$

Specimen Length $=230 \mathrm{~mm}$

Tab Material $=$ Mild Steel

Tab Length $=50 \mathrm{~mm}$

Tab Thickness $=2 \mathrm{~mm}$

Tab Adhesive = Epoxy Resin with Hardener

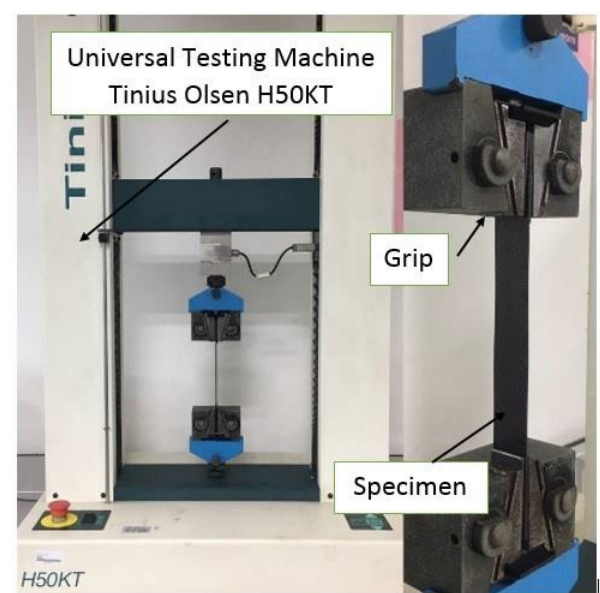

Fig. 6 - Universal testing machine Tinius Olsen H50KT 
The equipment used for the tensile test was Universal Testing Machine (UTM) Tinius Olsen H50KT as shown in Figure 6. Experimental procedure of ASTM D3039 and Standard Operating Procedure (SOP) of the tensile testing machine was followed when carrying out the test. Fibre Test (Stress) [Xhead] was selected at the test methods and the test settings were made. Hydraulics were turned on to raise or lower the fixtures of the tensile testing machine where then the tabbed part of the test specimen was clamped properly on the grip. Tensile loading was exerted till the test specimen fractures. Tensile experiment parameters adjusted in the test settings prior to starting the experiment. The parameter shown in Table 3 was obtained from a research paper which investigated the tensile properties of carbon fibre woven at $0 / 90^{\circ}[9]$.

Table 3 - Tensile test experiment parameters

\begin{tabular}{l} 
Tensile Test Experiment Parameters \\
\hline Load Range $=7000 \mathrm{~N}$ \\
Extension Range $=8 \mathrm{~mm}$ \\
Test Speed $=2 \mathrm{~mm} / \mathrm{min}$ \\
Sample Length $=230 \mathrm{~mm}$ \\
\hline
\end{tabular}

\section{Result and Discussion}

\subsection{Design Comparison}

In the attempt to distinguish the various conceptual designs of monorack arm, a brief design comparison is tabulated in Table 4 which shows the design comparison of final conceptual designs.

Table 4 - Design comparison

\begin{tabular}{|c|c|c|c|}
\hline $\begin{array}{l}\text { Existing / Final } \\
\text { Conceptual Designs }\end{array}$ & $\begin{array}{l}\text { Existing } \\
\text { Design } 1\end{array}$ & $\begin{array}{l}\text { Final Conceptual } \\
\text { Design } 2\end{array}$ & $\begin{array}{l}\text { Final Conceptual } \\
\text { Design } 3\end{array}$ \\
\hline \multicolumn{4}{|l|}{ Comparisons } \\
\hline Description & $\begin{array}{l}\text { Conventional Heavy-duty } \\
\text { rack existed in the market } \\
\text { whereby the tubular rack } \\
\text { has extension to the mid- } \\
\text { section of the motorcycle } \\
\text { to provide firm support } \\
\text { and maximize the stability }\end{array}$ & $\begin{array}{l}\text { Improvised design to form } \\
\text { a pair of tubular shaped } \\
\text { monorack arms at each } \\
\text { side of the motorcycle to } \\
\text { ensure superior support } \\
\text { upon loading }\end{array}$ & $\begin{array}{l}\text { Design is enhanced by } \\
\text { incorporating a single arm } \\
\text { that splits into two } \\
\text { separate arms to give a } \\
\text { superior support to the } \\
\text { base plate when load } \\
\text { comes in contact }\end{array}$ \\
\hline Number of Arm(s) & $\begin{array}{l}1 \text { arm at each side of the } \\
\text { motorcycle }\end{array}$ & $\begin{array}{l}2 \text { arms at each side of the } \\
\text { motorcycle }\end{array}$ & $\begin{array}{l}1 \text { arm with double split at } \\
\text { each side of the } \\
\text { motorcycle }\end{array}$ \\
\hline Shape of the Arm & Tubular Shape & Tubular Shape & Tubular Shape \\
\hline $\begin{array}{l}\text { Total Attachment Points } \\
\text { on the motorcycle frame }\end{array}$ & 4 Attachment points & 8 Attachment points & 4 Attachment points \\
\hline $\begin{array}{l}\text { Total Attachment Points } \\
\text { for the base plate }\end{array}$ & 4 Attachment points & 4 Attachment points & 4 Attachment points \\
\hline Type of Fasteners & $\begin{array}{l}\text { M8 Bolts \& Nuts to fasten } \\
\text { the arms } \\
\text { M5 Bolts \& Nuts to fasten } \\
\text { base plate }\end{array}$ & $\begin{array}{l}\text { M8 Bolts \& Nuts to fasten } \\
\text { the arms } \\
\text { M5 Bolts \& Nuts to fasten } \\
\text { base plate }\end{array}$ & $\begin{array}{l}\text { M8 Bolts \& Nuts to fasten } \\
\text { the arms } \\
\text { M5 Bolts \& Nuts to fasten } \\
\text { base plate }\end{array}$ \\
\hline
\end{tabular}

\subsection{ANSYS Static Structural Analysis of Existing Design 1}

Maximum deformation occurred at the base place support face where the force has been applied and gradually towards minimum at the fixed supports. Equivalent stress can be mostly observed to be at minimum level on the design 
and evenly distributed. Blue colored model indicates that the design was safe in relative to the force applied. Figure 7 shows the ANSYS structural results for existing Design 1.

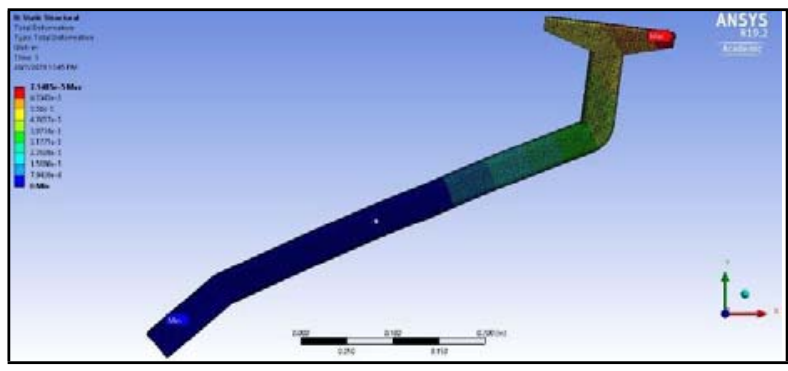

(a)

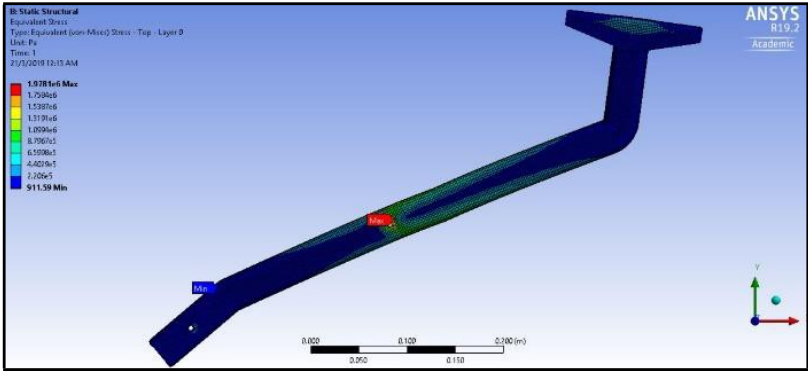

(b)

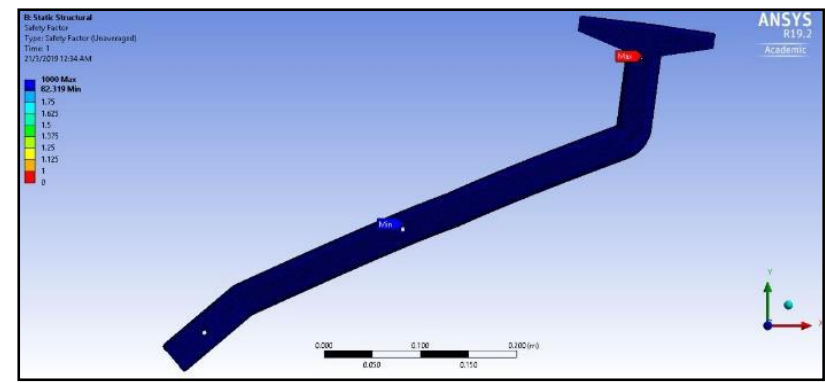

(c)

Fig. 7 - (a) Total deformation; (b) Equivalent (Von-Mises) stress; (c) Safety factor of ANSYS analysis for existing design 1

\subsection{ANSYS Static Structural Analysis of Final Conceptual Design 2}

Maximum deformation occurs at the top part of the geometry due to the applied force. Fixed supports face and particularly the bottom part of the geometry was experiencing the minimum deformation. Maximum equivalent stress takes place at fixed support bolt hole while the minimum deformation happens at majority surfaces of the design. As a result, the stress was evenly distributed for the design. Safety factor verifies that the design was definitely safe under static structural loading. Figure 8 shows the ANSYS structural results for final conceptual Design 2.

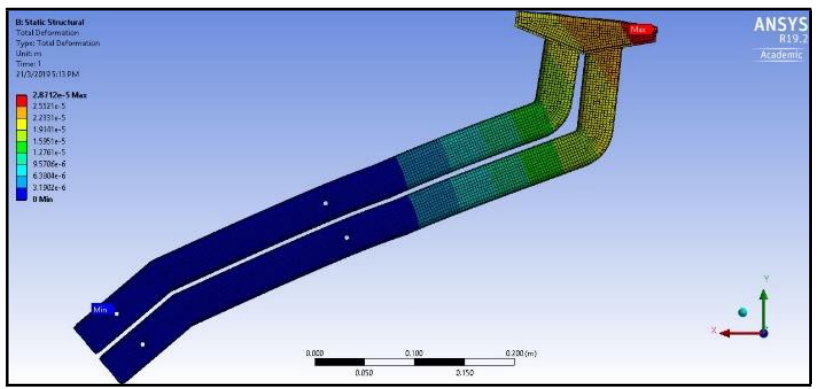

(a)

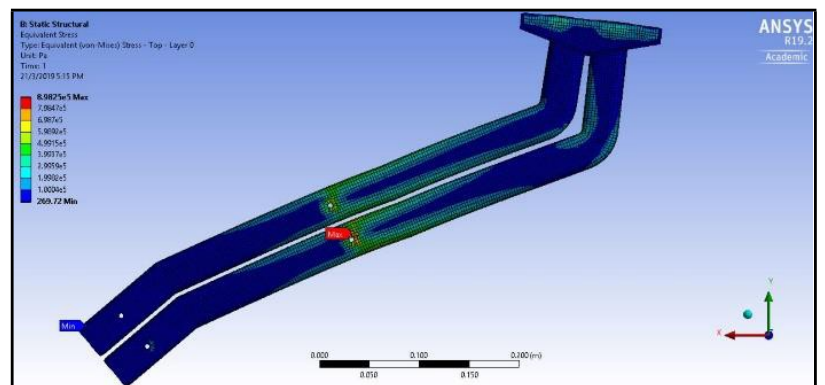

(b)

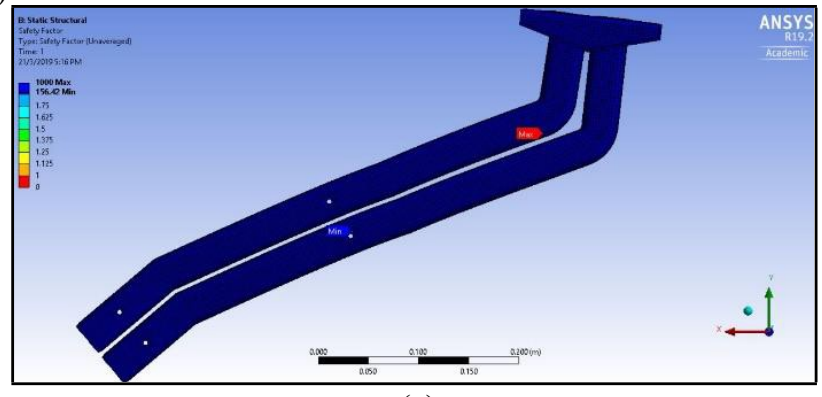

(c)

Fig. 8 - (a) Total deformation; (b) Equivalent (Von-Mises) stress; (c) Safety factor of ANSYS analysis for final conceptual design 2 


\subsection{ANSYS Static Structural Analysis of Final Conceptual Design 3}

Minimum deformation encountered at the surfaces away from the applied force. The deformation rate was considerably low to affect the integrity of the design under static loading. The equivalent stress was seen to be gradual throughout the geometry. Maximum equivalent stress was around the bolt hole due to the force from the base plate support which was exerted at the fixed support faces. High safety factor possessed indicates that the design was very safe. Figure 9 shows the ANSYS structural results for final conceptual Design 3.

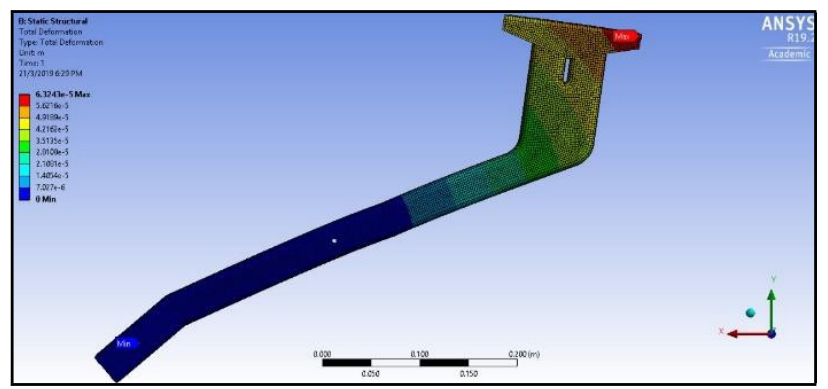

(a)

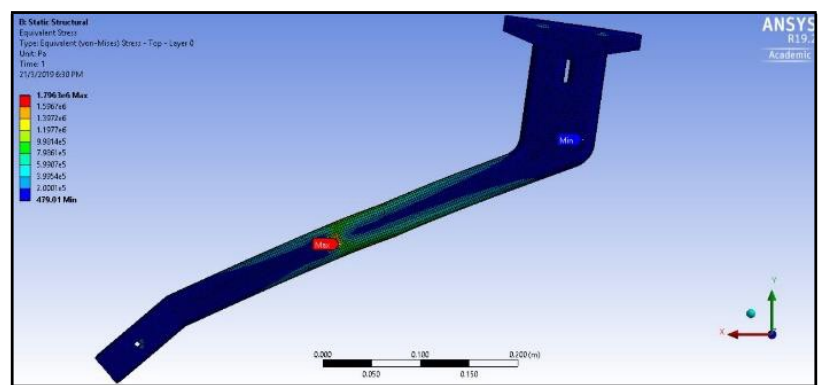

(b)

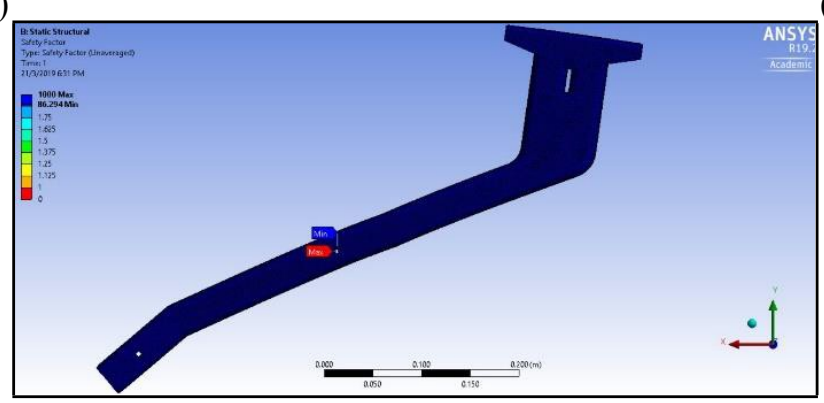

(c)

Fig. 9 - (a) Total deformation; (b) Equivalent (Von-Mises) stress; (c) Safety factor of ANSYS analysis for final conceptual design 3

\subsection{ANSYS Static Structural Analysis Comparison}

Final phase of this analysis was to compare ANSYS static structural results between the final conceptual designs of monorack arm. Under the analysis of epoxy carbon woven $(230 \mathrm{GPa})$ wet, total mass of Design 1 was the lowest due to the least proportion of material used for the design model while Design 3 comes second followed by Design 2. Moving on to the next analysis, total deformation of Design 2 was the smallest with $0.028712 \mathrm{~mm}$ at maximum. Equivalent stress was found to be the minimum again for Design 2. Safety factor affirms that all the designs were safe under the applied magnitude but however final analysis by safety factor was again favorable to Design 2 with 156.42 at minimum. Having said that, this final analysis verified that the Design 2 of final conceptual design with epoxy carbon woven $(230 \mathrm{GPa})$ wet was superior and secured a pole position therefore proving to be the preferable choice of design for monorack arm. Table 5 shows the static structural analysis comparison between all the final conceptual designs using epoxy carbon woven $(230 \mathrm{GPa})$ wet.

Table 5 - Static structural analysis comparison between epoxy carbon woven (230 GPa) wet

\begin{tabular}{|c|c|c|c|c|c|c|c|c|}
\hline Code & Material & $\begin{array}{l}\text { Mass } \\
(\mathbf{k g})\end{array}$ & Total & $\begin{array}{l}\text { eformation } \\
\text { (mm) }\end{array}$ & Eq1 & $\begin{array}{l}\text { alent Stress } \\
\text { (MPa) }\end{array}$ & Safet & actor \\
\hline \multirow{2}{*}{ ED1 } & \multirow{2}{*}{$\begin{array}{l}\text { Epoxy Carbon Woven } \\
\text { (230 GPa) Wet }\end{array}$} & \multirow{2}{*}{0.15778} & Ma & 0.07148 & Ma & 1.9781 & Ma & 1000 \\
\hline & & & Mi & 0 & Mi & 0.0009115 & $\mathbf{M i}$ & 82.31 \\
\hline \multirow{2}{*}{$\mathrm{CD} 2$} & \multirow{2}{*}{$\begin{array}{l}\text { Epoxy Carbon Woven } \\
\text { (230 GPa) Wet }\end{array}$} & \multirow{2}{*}{0.28977} & Ma & 0.02871 & Ma & 0.89825 & Ma & 1000 \\
\hline & & & Mi & 0 & Mi & 0.0002697 & Mi & 156.4 \\
\hline \multirow{2}{*}{ CD3 } & \multirow{2}{*}{$\begin{array}{l}\text { Epoxy Carbon Woven } \\
\text { (230 GPa) Wet }\end{array}$} & \multirow{2}{*}{0.18652} & Мa & 0.06324 & Мa & 1.7963 & Ма & 1000 \\
\hline & & & Mi & 0 & Mi & 0.0004790 & $\mathbf{M i}$ & 86.29 \\
\hline
\end{tabular}

ED1 = Existing Design 1, CD2 = Conceptual Design 2, Conceptual D3 = Design 3 


\subsection{Tensile Test Experimental Analysis}

Tensile test experimental procedure was carried out to run the tensile load on the test specimens. Upon the fracture of the test specimens, graph of force versus extension was generated by the QMat 5.45 T-Series - 50K software. Maximum load before failure $(\mathrm{N})$ and the total extension $(\mathrm{mm})$ was obtained from the graph. Graph of force versus extension generated by the software for all the test specimens of plain weave carbon fibre and twill weave carbon fibre were compiled as shown in Figure 9. From the Figure 9 (a) and (b), graphs of plain weave specimens were seen to have higher force before failure of the test specimens. Ideally higher force is experienced in plain weave specimens is because of the fabric weaving style which has the tightest weave with warp and weft are weaved one under and one over consecutively unlike the twill fabric. This actually results in excellent symmetry and balance when imbedded within the epoxy matrix while giving highest resistance to fracture when subjected to load. Also, plain weave specimen gives more strength in the direction of weave during tensile loading [12]. Extension experienced by both plain weave specimens and twill weave specimens were nearly equal. Theoretically twill weave fabric which the warp and weft are weaved two under and over consecutively has better draping capability due to the lowest crimp. This pattern makes the fabric elastic to achieve greater extension when a force is applied compared to plain weave fabric. However, the slight deviation of the graph is due to the improper bonding and alignment of tab material to the test specimens which raised imbalance stresses on the test specimens. On the other hand, visual inspection of the test specimens for surface abnormalities such as notches and edge delamination were recommended prior to starting the experiment.

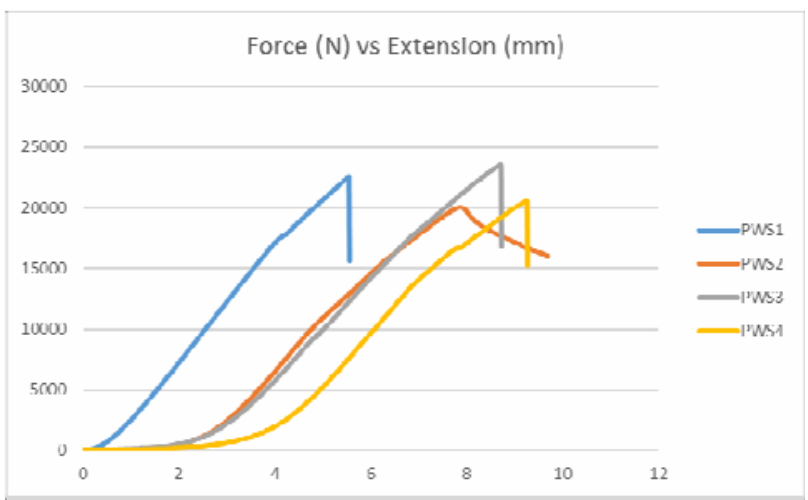

(a)

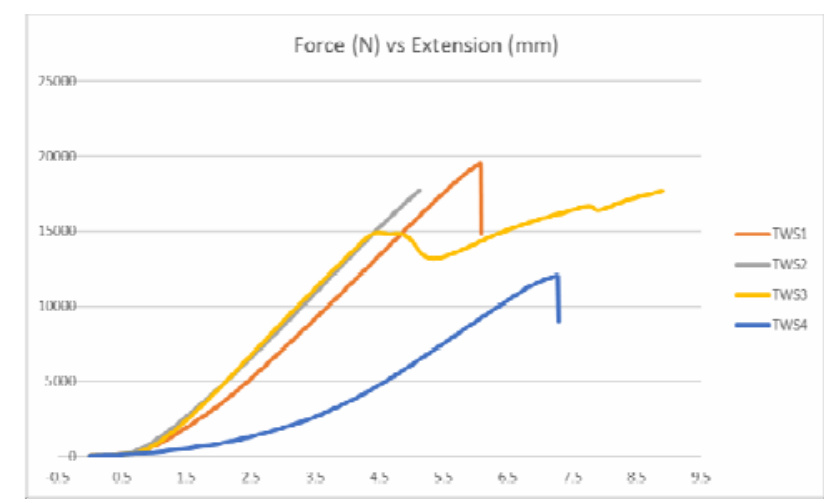

(b)

Fig. 9 - (a) Plain weave test specimens; (b) Twill weave test specimens of force versus extension graph

Table 6 - Tensile test results comparison of plain weave and twill weave specimens

\begin{tabular}{ccccccc}
\hline Code & $\begin{array}{c}\text { Maximum Load } \\
\text { before Failure (N) }\end{array}$ & $\begin{array}{c}\text { Extension } \\
\mathbf{( m m )}\end{array}$ & $\begin{array}{c}\text { Ultimate Tensile } \\
\text { Strength (MPa) }\end{array}$ & Strain & $\begin{array}{c}\text { Extension at } \\
\text { Break (\%) }\end{array}$ & $\begin{array}{c}\text { Young's } \\
\text { Modulus } \\
\text { (GPa) }\end{array}$ \\
\hline PWS1 & 22575 & 5.5575 & 451.5 & 0.02416 & 2.4163 & 18.6856 \\
PWS2 & 20075 & 9.6900 & 401.5 & 0.04213 & 4.2130 & 9.5300 \\
PWS3 & 23575 & 8.7400 & 471.5 & 0.03800 & 3.8000 & 12.4079 \\
PWS4 & 20600 & 9.2700 & 412.0 & 0.04030 & 4.0304 & 10.2233 \\
\hline AVE & $\mathbf{2 1 7 0 6}$ & $\mathbf{8 . 3 1 4 4}$ & $\mathbf{4 3 4 . 1}$ & $\mathbf{0 . 0 3 6 1 5}$ & $\mathbf{3 . 6 1 4 9}$ & $\mathbf{1 2 . 7 1 1 7}$ \\
\hline TWS1 & 19480 & 6.0900 & 389.6 & 0.02648 & 2.6478 & 14.7130 \\
TWS2 & 17740 & 5.1375 & 354.8 & 0.02234 & 2.2337 & 15.8818 \\
TWS3 & 17680 & 8.9000 & 353.6 & 0.03870 & 3.8696 & 9.1370 \\
TWS4 & 12050 & 7.2825 & 241.0 & 0.03166 & 3.1663 & 7.6121 \\
\hline AVE & $\mathbf{1 6 7 3 8}$ & $\mathbf{6 . 8 5 2 5}$ & $\mathbf{3 3 4 . 8}$ & $\mathbf{0 . 0 2 9 8 0}$ & $\mathbf{2 . 9 7 9 4}$ & $\mathbf{1 1 . 8 3 6 0}$ \\
\hline
\end{tabular}

PWS1 = Plain Weave Specimen 1, PWS2 = Plain Weave Specimen 2, PWS3 = Plain Weave Specimen 3, PWS4 = Plain Weave Specimen 4, TWS1 = Twill Weave Specimen 1, TWS2 = Twill Weave Specimen 2, TWS3 = Twill Weave Specimen 3, TWS4 = Twill Weave Specimen 4

\subsection{Tensile Test Experimental Result}

Final phase of the experimental analysis was to compare between two type of woven fabrics. From the experimental analysis, plain weave needed higher force than twill weave for the failure to take place in the test 
specimen. Higher extension in plain weave test specimens during the tensile loading shows that the material exhibits certain plastic region to withstand the load from rupture. Ultimate tensile strength or also referred as maximum stress was also seen to be greater in plain weave specimens compared to twill weave specimens. Plain weave specimens needed more load to begin the elongation which eventually ruptures shortly after. Amount of deformation in plain weave when subjected to loading was higher than in twill weave therefore resulted in better strain. Slightly higher young's modulus in plain weave shows that the material was stiffer than twill weave composite. To conclude the analysis, plain weave woven fabric was proven to show better mechanical properties under tensile loading which was crucial for the static loading application of monorack arm. Tensile test results for the plain and twill specimens are tabulated in Table 6.

\subsection{Conclusion}

This paper deals with design and analysis of carbon fibre composite monorack arm. Three conceptual models of Heavy-Duty Rack (HRV) monorack arm were initiated which were then optimized and enhanced to improve the structural ability to work under static stress. Substantial considerations were given in terms of design considerations to produce the final model of conceptual designs of monorack arm. For the purpose of experimental investigation, two types of carbon fibre composite samples were fabricated which consist of plain weave woven fabric and twill weave woven fabric as reinforcements. Analysis of fabricated samples were done with respect to tensile test experiment where plain weave woven fabric composite was seen to possess great mechanical strength in comparison to twill weave composite. Final conceptual designs were computed using ANSYS workbench to solve for finite element analysis. Design 2 of final conceptual design using epoxy carbon woven $(230 \mathrm{GPa})$ wet was chosen to be fit for the design of monorack arm. In conclusion, the objectives of the project have been achieved as Design 2 was the ideal choice for monorack arm with epoxy carbon of plain weave woven fabric with total deformation of $0.028712 \mathrm{~mm}$ at maximum, minimum equivalent stress of $0.00026972 \mathrm{MPa}$ and safety factor of 156.42 at minimum compared to among other designs.

\section{References}

[1] Majid A., Khabiri M. M., (2016). Experimental Study on the Effect of Glass and Carbon Fibers on Physical and Micro-Structure Behavior of Asphalt. International Journal of Integrated Engineering, Vol. 8 No. 3 (2016), p. 1-8.

[2] J. Jayaprakash, et. al., (2015). Experimental and Finite Element Studies on CFF Strengthened RC Rectangular Beams in Shear. International Journal of Integrated Engineering, Vol. 7 No. 1 (2015), pp. 29-38.

[3] Jeyaprakash, P., Prabhakaran, V., \& Devaraju, A. (2018). Experimental and Numerical Analysis of Carbon Epoxy Fibre Composite under Buckling Load. Materials Today: Proceedings, 5(6), 14526-14530.

[4] Eksi, S., \& Genel, K. (2017). Comparison of mechanical properties of unidirectional and woven carbon, glass and aramid fiber reinforced epoxy composites. Acta Physica Polonica A, 132(3), 879-882.

[5] Sun, W., Guan, Z., Li, Z., Zhang, M., \& Huang, Y. (2017). Compressive failure analysis of unidirectional carbon/epoxy composite based on micro-mechanical models. Chinese Journal of Aeronautics, 30(6), 1907-1918.

[6] Shirvanimoghaddam, K., Hamim, S. U., Karbalaei Akbari, M., Fakhrhoseini, S. M., Khayyam, H., Pakseresht, A. H., Naebe, M. (2017). Carbon fiber reinforced metal matrix composites: Fabrication processes and properties. Composites Part A: Applied Science and Manufacturing, 92, 70-96.

[7] Farsani, R. E., \& Fazaeli, R. (2012). Applications of Carbon Fibers Produced from Polyacrylonitrile Fibers, 6(8), 836-839.

[8] Dér, A., Kaluza, A., Kurle, D., Herrmann, C., Kara, S., \& Varley, R. (2018). Life Cycle Engineering of Carbon Fibres for Lightweight Structures. Procedia CIRP, 69 (May), 43-48.

[9] Wang, T., \& Li, Y. (2015). Design and analysis of automotive carbon fiber composite bumper beam based on finite element analysis. Advances in Mechanical Engineering, 7(6), 1-12.

[10] Dhanraj Pamar, J., Balu Naik, B., Hema Latha, O., \& Sayeed Ahmed, G. M. (2015). Experimental Investigation of Bi Directional Carbon Fiber Composite. Materials Today: Proceedings, 2(4-5), 3008-3016.

[11] Rahmani, H., Najafi, S. H. M., \& Ashori, A. (2014). Mechanical performance of epoxy/carbon fiber laminated composites. Journal of Reinforced Plastics and Composites, 33(8), 733-740.

[12] Campos, Marcelo C., Soufen, Carlos A., Bueno, Marcos P., Imaizumi, Momotaro (2014). Comparative Study Of Mechanical Properties Of Woven Of Carbon Fiber Twill And Plain Weave In Laminates With Epoxy Matrix. 2nd Brazilian Conference On Composite Materials.

[13]ASTM International. (2000). ASTM D 3039M - Standard Test Method for Tensile Properties of Polymer Matrix Composite Materials. Annual Book of ASTM Standards, 15.03, 1-13. 